\title{
Relationship Between a Modified Thomas Test and Leg Range of Motion in Australian-Rules Football Kicking
}

\author{
Warren Young, Peter Clothier, Leonie Otago, Lyndell Bruce, \\ and David Liddell
}

Context: Flexibility tests are sometimes thought to be related to range of motion in dynamic activities, but such a relationship remains to be determined. Objective: To determine the correlation between flexibility and hip and knee angles in Australian football kicking. Design: Correlation. Setting: Biomechanics laboratory. Participants: 16 Australian Rules football players. Main Outcome Measures: Hip and knee angles of the preferred kicking leg in a relaxed position were determined with a modified Thomas test. Maximum hip extension, the knee-flexion angle in this position, the maximum knee-flexion angle, and the hip angle at this position during the swing phase of maximum-effort drop-punt kicks were determined. Results: Significant correlations were found between hip flexibility and maximum hip extension $(r=.65, P<$ $.01)$ and hip angle at the maximum knee-flexion angle $(r=.70, P<.01)$. Conclusions: The data indicate a moderate association between hip flexibility and hip angles during kicking. Key Words: flexibility, hip extension, knee flexion

Young W, Clothier P, Otago L, Bruce L, Liddell D. Relationship between a modified Thomas test and leg range of motion in Australian-Rules football kicking. I Sport Rehabil. 2003;12:343-350. (O) 2003 Human Kinetics Publishers, Inc.

Kicking has been described as a "throwlike" movement pattern whereby distal segments are allowed to lag behind the proximal segments as they move forward. ${ }^{1}$ In Australian Rules (AR) football, the drop-punt kick is an important skill and must be performed with the objective of attaining both distance and accuracy. Orchard et $\mathrm{al}^{2}$ described the muscle activity during the drop-punt kick with the use of electromyography (EMG). During the "wind-up," when there is hip and knee flexion, the quadriceps produced a high level of activity. The authors suggested that during this phase, the rectus femoris contracted concentrically, as well as other hip flexors, and the other quadriceps acted eccentrically to decelerate the knee flexion. During the next phase of hip flexion and knee extension the quadriceps were also highly active. In soccer kicking, EMG analysis has also shown that quadriceps activity is relatively high during eccentric work when the kicking leg is back in the "cocked" position.

The authors are with the School of Human Movement \& Sport Sciences, University of Ballarat, Ballarat, Victoria 3353 Australia. 
From a biomechanical standpoint, the objective of kicking for distance is to achieve a high foot velocity at the instant of impact with the ball. The nature of the contact between foot and ball can also have a profound influence on the postimpact ball velocity. ${ }^{4}$ Foot velocity is influenced by a sequential summation of forces from muscles acting around the pelvis, hip, knee, and ankle joints. Because of the impulse-momentum relationship, ${ }^{4}$ generally the greater the distance or time over which the swinging leg can move, the greater the potential to achieve a high final velocity of the foot. For this reason, it would be a disadvantage for a kicker to have limitations from the musculoskeletal system that could limit range of motion (ROM) at the joints. In relation to kicking, short or tight hip flexors and quadriceps could potentially limit hip and knee ROM and, in turn, foot speed at impact. ${ }^{5}$ Reduced extensibility of tissues around the hip and knee joints are thought to be related to injury risk. For example, it has been suggested that a shortened rectus femoris might be related to knee pain in soccer players. ${ }^{6}$ Kicking might be similar to gait, wherein it is thought that tight iliopsoas muscles and reduced hip extension might lead to anterior pelvic tilt as a compensation mechanism, placing increased stress on the lumbopelvic region. ${ }^{78}$

The Thomas test and various modifications of it have been widely used by clinicians to assess hip-flexor flexibility in athletes. ${ }^{9-12}$ By measuring hip and knee angles of the unconstrained leg, it is possible to evaluate the flexibility of the iliopsoas and rectus femoris muscles..$^{10,13}$ The underlying assumption is that this static test of flexibility has predictive ability in relation to dynamic activities. Godges et $\mathrm{al}^{14}$ reported that subjects with shortened hip flexors increased their hip-extension angle by $4^{\circ}$ during walking and running after 6 minutes of static stretching of these muscles. This short-term improvement in flexibility was accompanied by an increase in gait economy, thought to be a result of improved "neuromuscular balance." In a follow-up study, Godges et $\mathrm{al}^{7}$ reported significant gains in hipextension flexibility after 6 training sessions of static stretching of the hip flexors. There were no significant changes in running economy, however, after the 3-week training period. One reason suggested by the authors for this unexpected finding was that the Thomas test placed the subjects in a supine position, which might not correlate to function in complex activities performed in an upright position such as walking and running.

Some research has calculated correlation coefficients for hip extension from a modified Thomas test and hip extension during gait. Using patients with various disorders and hip-flexion contractures, Lee et $\mathrm{al}^{8}$ reported a statistically significant $(r=.41, P<.01)$ but "fairly weak" relationship between the values generated from the Thomas test and walking at a "comfortable speed." More recently, a study involving elite track and field athletes demonstrated virtually no correlation $(r=.004, P>.05)$ between hip-extension flexibility and peak hip extension while running at $20 \mathrm{~km} /$ h." The authors concluded that the ability for clinicians to predict hip 
extension in running from Thomas-test results is limited, possibly because hip extension in running is influenced by complex neuromotor patterns rather than static flexibility alone.

Although there are some data relating Thomas-test results to dynamic activities, such associations have not been previously investigated with kicking in AR football. Therefore, the purpose of this study was to determine the correlation between hip and knee angles in a modified Thomas test and in kicking for maximum distance. If there are low relationships between hip and knee angles in the Thomas test and the corresponding angles in kicking, the practice of using this clinical test to predict ROM in kicking would be questionable.

\section{Methods}

\section{Design}

The study employed a correlation design with the focus on describing the relationship between hip and knee angles in a modified Thomas test of static flexibility (independent variables) and hip and knee angles in the sport skill of punt kicking (dependent variables).

\section{Subjects}

Sixteen men between 18 and 33 years of age volunteered to participate in the study, providing informed consent in writing. The project was approved by the university ethics committee. The participants were required to have played AR football competitively in the preceding 12 months and to be free of any injury or disorder that could cause pain or limit their participation. All subjects designated their right leg as their preferred kicking leg.

\section{Testing Procedures}

The subjects attended the laboratory on 2 occasions. The first was to become familiarized with all of the procedures, and the second, for data collection. On arrival at the laboratory, the subjects were prepared by marking various landmarks with a semipermanent pen and attaching reflective motion-analysis markers to these points. The markers were placed in the following positions: iliac crest, hip (trochanterion), knee (femur-tibia joint line), ankle (lateral malleolus), heel (calcaneus), and foot (head of fifth metatarsal). These markings were used to generate a stick figure to identify pelvic, thigh, shank, and foot positions and corresponding joint angles for the Thomas test and football kicking.

Participants then performed a standardized warm-up starting with 5 minutes of running at $10 \mathrm{~km} / \mathrm{h}$ on a treadmill. Three static stretching exercises for the quadriceps and hip-flexor muscles were then performed consisting of 3 repetitions of $30 \mathrm{~s}$ on each side in an alternating order for 
each exercise (Figure 1). In the first exercise, the subject lay in a prone position with the hip hyperextended. One of the investigators moved the ankle to flex the knee. The second exercise required the subject to place 1 foot in front of the body and the knee of the other leg on the floor so that the hip was in hyperextension. The lower leg was again moved to produce maximum knee flexion without pain. In the third exercise, the subject adopted a standing split position (with 1 foot forward and 1 backward) and lowered the body to achieve maximum hip hyperextension while maintaining a neutral pelvic position. Finally, the participants performed 6 submaximaleffort kicks progressing from $50 \%$ to $95 \%$ of their perceived maximum and 1 kick at $100 \%$ (maximum distance). After this warm-up, the modified Thomas test was conducted.
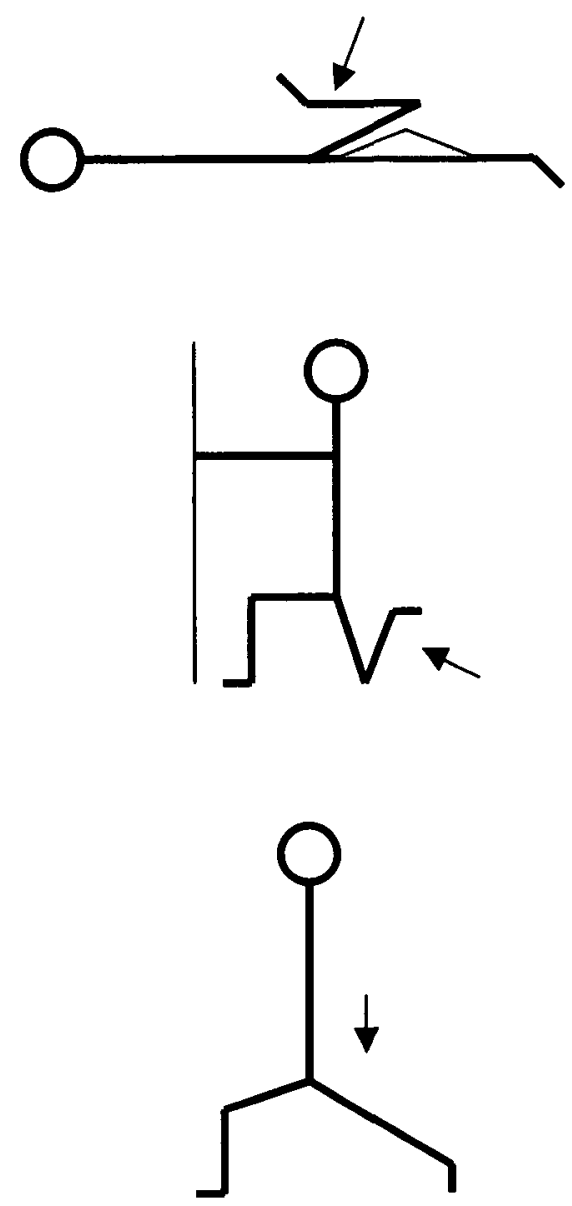

Figure 1 Stretching exercises used in the warm-up. 


\section{Modified Thomas Test}

The subject lay supine on a table so that his gluteal fold was located at the end of the table, and he held both knees to his chest. Then he lowered his right leg until it came to rest, at which point he was instructed to keep the leg as relaxed as possible. Thomas-test joint angles were calculated from a leg position corresponding with a posterior pelvic tilt (lumbar spine on table), which was defined as a horizontal alignment of the iliac crest and trochanterion landmarks. If the alignment was judged as not being horizontal, the subject was asked to move the contralateral knee closer to or farther from the chest. For example, bringing the knee closer to the chest produced flexion of the lumbar spine.

This stationary body position was videotaped for approximately 3 seconds. Video images were recorded using a Panasonic MS5 S-VHS video camcorder set to operate at $50 \mathrm{~Hz}$. The camera was positioned $11.5 \mathrm{~m}$ perpendicular to the plane of motion of the leg. An exposure time of $500 / \mathrm{s}$ was used, and the video images were recorded on a Panasonic VCR (model AG-7350-E). This analysis yielded 2 measures of flexibility-hip extension and knee flexion-which served as independent variables.

\section{Kicking}

After the Thomas test, the participants performed 6 maximum-effort droppunt kicks with the right foot in the laboratory into a net approximately 10 m away.

Kicking trials were recorded using a Peak video camcorder (HSC-200PS) set to record at $200 \mathrm{~Hz}$. An exposure time of $1000 / \mathrm{s}$ was used, and the video images were recorded on a Panasonic VCR (model AG-5700). This camera was positioned $13.5 \mathrm{~m}$ perpendicular to the plane of motion of the leg during kicking.

\section{Analysis of Flexibility and Kicking Variables}

Two-dimensional analysis via a Peak Motus 32 (Version 6.1) motion-analysis system was performed on all recorded video images. All 6 landmarks for each test trial were digitized using a combination of automatic and manual methods. The iliac crest, trochanterion, knee, and ankle were digitized, from which hip- and knee-flexion angles were calculated from the Thomas test. If the thigh position was lower than the horizontal line made by the iliac crest and trochanterion, the hip was considered to be hyperextended (Figure 2), and the angle recorded was given a positive value. The knee angle was expressed as the amount of knee flexion (Figure 2).

Kicking trials were digitized from last foot contact with the ground to ball contact of the kicking leg. Foot speed at contact was measured as the speed of the foot (head of fifth metatarsal) immediately before ball contact. 


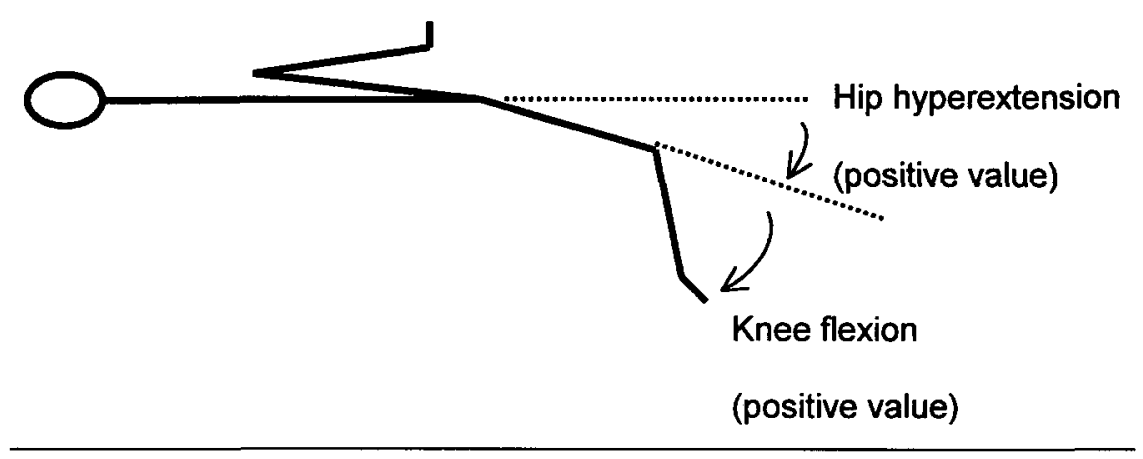

Figure 2 Diagram illustrating hip and knee angles.

Computed data were smoothed using a Butterworth filter with a prescribed cutoff of $10 \mathrm{~Hz}$. All kicking trials were digitized, with the trial containing the greatest foot velocity before contact retained for analysis. The kicking analysis produced 4 dependent variables: maximum hip extension, knee flexion at maximum hip extension, maximum knee flexion, and the hip angle at maximum knee flexion.

The accuracy of the digitizing process was enhanced by using the magnifier function of the analysis system, which increases the size of the reflected markers. To check for the repeatability of the digitizing for the Thomas test, a trial for 1 subject was repeated 10 times. This yielded coefficients of variation of $2.5 \%$ and $0.9 \%$ for the hip and knee angles, respectively.

\section{Statistics}

Pearson correlation coefficients were computed for the 2 angles generated from the Thomas test and for the 4 kicking variables. Statistical significance was accepted at the $P<.05$ level.

\section{Results}

The mean \pm SD results for the modified Thomas test were $13.7^{\circ} \pm 7.8^{\circ}$ and $49.8^{\circ} \pm 7.7^{\circ}$ for the hip and knee, respectively. The mean angles from the kicking analyses were $8.0^{\circ} \pm 5.2^{\circ}$ for maximum hip extension, $69.1^{\circ} \pm$ $17.6^{\circ}$ for knee flexion at maximum hip extension, $107.8^{\circ} \pm 9.2^{\circ}$ for maximum knee flexion, and $-5.5^{\circ} \pm 6.8^{\circ}$ for the hip angle at maximum knee flexion.

The Thomas-test hip angle correlated significantly $(P<.01)$ with some of the kicking variables-maximum hip-extension angle $(r=.65)$ and the hip angle at maximum knee flexion $(r=.70)$ - but not significantly $(P>.05)$ with knee flexion at maximum hip extension $(r=-.20)$ and with maximum knee flexion during the kick $(r=.14)$. The Thomas-test knee angle produced 
low and nonsignificant correlation coefficients with all the kicking variables: maximum hip extension (.14), knee flexion at maximum hip extension (.33), maximum knee flexion (.01), and hip angle at maximum knee flexion (.08).

\section{Comments}

The mean hip $\left(13.7^{\circ}\right)$ and knee $\left(49.8^{\circ}\right)$ angles in the Thomas test were comparable to the means reported by Harvey ${ }^{9}\left(11.9^{\circ}\right.$ and $52.5^{\circ}$, respectively) for athletes from a range of sports. Despite varied protocols used to establish norms, these results probably indicate normal flexibility, which is of interest for footballers who perform very high repetitions of kicking and can be expected to have muscle tightness and poor flexibility.

The most important findings of this study were the significant moderate correlations between hip flexibility and the hip angles during kicking. This suggests that the subjects with the best hip-extension flexibility tended to achieve the greatest hip extension during kicking. The relationship between the static measure of flexibility and the hip and knee positions achieved during kicking was stronger than in previous research that investigated gait. For example, Lee et $\mathrm{l}^{8}$ reported a correlation coefficient of only .41 during walking, and Schache et $\mathrm{al}^{11}$ found no relationship with running.

Both kicking variables that correlated significantly with hip flexibility were obtained when the knee was flexed. Because the rectus femoris is a biarticular muscle, its extensibility would be expected to influence the hip angle during kicking. The same situation is encountered in the Thomas test, whereby the hip angle is obtained when the knee is flexed. In running, the knee is extended when the hip is in maximum extension, that is, immediately after ground contact is lost. This might explain why stronger relationships were found in the present study than in the earlier research on running. Another possible reason is that kicking for maximum distance encourages an inertial lag of the kicking leg, thereby significantly stretching the hip-flexor muscles. The studies using gait ${ }^{8,11}$ involved submaximal speeds, which might have not required a high level of hip flexibility. The present study was also unique in that the angles obtained both in the Thomas test and in kicking were generated by using the same measurement procedures (eg, placement of joint markers and videotape analysis).

The Thomas test has been modified in various ways such as attempting to eliminate the influence of the rectus femoris by holding the tested leg in a position of full knee extension. ${ }^{12}$ It could be speculated that this protocol would not be as predictive of hip extension in kicking when the knee is flexed.

Within the constraints of a 2-dimensional analysis of kicking, it can be concluded that the present study provides some support for a relationship between hip flexibility as measured by a modified Thomas test and hip 
extension in kicking in AR football. The relationship between static flexibility and kicking might be more fully understood by a 3-dimensional analysis of kicking. Two questions of interest for future research are (1) Does good static hip flexibility allow the swinging leg to travel over a longer path and generate greater foot velocity at impact with the ball? and (2) Do good static hip flexibility and good hip extension in kicking prevent excessive anterior pelvic tilt during kicking and reduce the risk of injury in the lumbopelvic region?

\section{References}

1. Kreighbaum E, Barthels KM. Biomechanics: A Qualitative Approach for Studying Human Movement. 2nd ed. New York, NY: Macmillan; 1985.

2. Orchard J, Walt S, McIntosh A, Garlick D. Muscle activity during the drop punt kick. In: Spinks W, Reilly T, Murphy A, eds. Science and Football IV. London: Routledge; 2002:32-43.

3. De Proft E, Clarys JP, Bollens E, Cabri J, Dufour W. Muscle activity in the soccer kick. In: Reilly T, Lees A, Davids K, Murphy WJ, eds. Science and Football. London: E \& FN Spon; 1988:434-440.

4. Hay JG. The Biomechanics of Sports Techniques. 4th ed. Englewood Cliffs, NJ: Prentice-Hall; 1994.

5. Rath D. Biomechanics of Kicking. Level 2 Coaching Course. Canberra: Australian Institute of Sport; 2002.

6. Weber M, Baumann JU. Muscle contractures of soccer players-relationship with knee complaints and the effect of stretching exercises. In: Reilly T, Lees A, Davids K, Murphy WJ, eds. Science and Football. London: E \& FN Spon; 1988:219223.

7. Godges JJ, MacRae PG, Engelke KA. Effects of exercise on hip range of motion, trunk muscle performance, and gait economy. Phys Ther. 1993;73:468-477.

8. Lee LW, Kerrigan DC, Della Croce U. Dynamic implications of hip flexion contractures. Am J Phys Med Rehabil. 1997;76:502-508.

9. Harvey D. Assessment of the flexibility of elite athletes using the modified Thomas test. Br J Sports Med. 1998;32:68-70.

10. Harvey D, Mansfield C. Measuring flexibility for performance and injury prevention. In: Gore C, ed. Physiological Tests for Elite Athletes. Champaign, Ill: Human Kinetics; 2000:98-113.

11. Schache AG, Blanch PD, Murphy AT. Relation of anterior pelvic tilt during running to clinical and kinematic measures of hip extension. Br J Sports Med. 2000;34:279-283.

12. Tyler T, Zook L, Brittis D, Gleim R. A new pelvic tilt detection device: Roentgenographic validation and application to assessment of hip motion in professional ice hockey players. J Orthop Sports Phys Ther. 1996;24:303-308.

13. Kendall FP, McCreary EK, Provance PG. Muscles Testing and Function. 4th ed. Baltimore, Md: Williams \& Wilkins; 1993.

14. Godges JJ, MacRae H, Longdon C, Tinberg C, MacRae P. The effects of two stretching procedures on hip range of motion and gait economy. J Orthop Sports Phys Ther. 1989;10:350-357. 
Copyright of Journal of Sport Rehabilitation is the property of Human Kinetics Publishers, Inc. and its content may not be copied or emailed to multiple sites or posted to a listserv without the copyright holder's express written permission. However, users may print, download, or email articles for individual use. 